\title{
PSYCHE.
}

\section{THE MOUTHPARTS OF THE NEMATOCEROUS DIPTERA, II.}

\author{
BY VERNON L. KELLOGG, STANFORD UNIVERSITY, CALIFORNIA.
}

In the following account of the mouthparts of the Nematocera, that nomenclature of parts is used which represents the interpretation of the mouthpart homologies most widely accepted at the present time. As some nomenclature is necessary and the author's interpretation of the homologies may not, consistently with the point of view adopted in this study, be set out until the testimony of the study has been presented, the nomenclature of common acceptation is naturally used. As the mouthparts of one representative, at least, of each family, are figured from drawings made by camera lucida, the descriptions of the various parts are made very brief. Owing to the limitations of space, in most instances the mouthparts are figured in situ alone; in some instances, however, figures of two or three of the isolated parts are given. As all the Nematocerous mouthparts are alike in essential character and arrangement, the figures of the cross sections of the mouthparts of Blepharocera capitata illustrate nearly as well the conditions presented by any other of the mandiblepossessing Nematocerous females.

\section{Blepharoceridae.}

Liponeura? sp. This species is a large undescribed Blepharocerid, taken by me in California, and should probably be made the type of a new genus. The mouthparts of the female consist of the following well developed, independent and easily distinguishable parts shown in figure I in situ to reveal the relative size and natural position with regard to each other: a labrum-epipharynx (l.ep), a pair of mandibles $(m d)$, a pair of maxillae $(m x)$, a labium (li) and a hypopharynx (hyp).

The labrum-epipharynx (fig. I A, 1. $e p$ ) is elongate, slender, and pointed, and bears numerous taste pits (?) on its lower (inner) surface which is concave.

The mandibles (fig. $\mathrm{I} \mathrm{A,} m d$ ) are long, slender, well chitinized, and each is sharply, finely and conspicuously serrate along the distal half of the inner margin. The mandibles are articulated wiih the head capsule wholly distinctly from the other mouthparts. 
The maxillae (fig. I $\mathrm{A}, m x$ ) consist of a single short, tapering, blade-like, thin but well chitinized maxillar lobe $(m x . l)$ and a long, slender, 5-segmented palpus $(m x)$. Lobe and palpus arise from a basal sclerite, which shows no differentiation into cardo and stipes, and may be taken to represent these two sclerites completely fused.

The labium (fig. I A, li) consists of a strong elongate basal sclerite which presents indications of a line of fusion of sub-mentum and mentum, and a pair

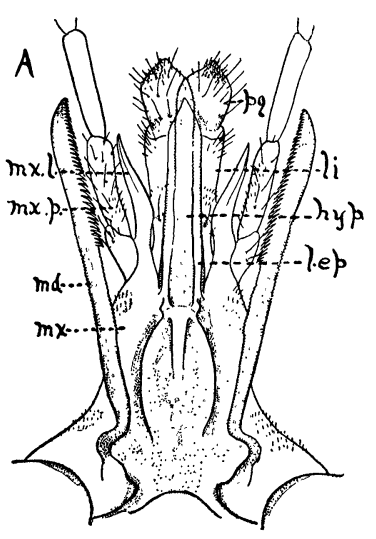

Fig. I, A, Mouthparts of Liponeura ? sp., o; $l$. ep labrum-epipharynx, $m d$ mandible, $m x$. maxillae, $m x$. $l$ maxillar lobe, $m x . p$ maxillar palpus, $l i$ labium, $p g$ paraglossa, hyphypopharynx; B, Cross section near the base of the mouthparts of Blepharocera capitata $\$$; $C$, Cross section near the tip of mouthparts of Blepharocera capitata $q$; lettering in $\mathrm{B}$ and $\mathrm{C}$ same as in $\mathrm{A}$, with addition in $\mathrm{C}$ of $g l$ glossa, and substitution of $l b$ for $l$. epp (= labrum-epipharynx).

of free fleshy terminal lobes, the paraglossae $(p g)$ (see account of Blepharocera capitata). These terminal lobes have no pseudo-tracheae. There are no palpi.

The hypopharynx (fig. I A, hyp) is as long as or slightly longer than the labrum-epipharynx, is narrower, and although thin, well-chitinized. It lies along the dorsal surface of the labium underneath the labrum-epipharynx.

As shown in figure I $\mathrm{A}$, the mouthparts, excepting the mandibles, are carried somewhat forward by the extension of their bases or of the frontal part of the head-capsule. The various parts of the mouth dissect apart readily.

Blepharocera capitata. The mouthparts of the female resemble the mouthparts of the previously described member of the family with, however, certain interesting differences in the labium. The basal sclerite of the labium terminates proximally in a strongly chitinized sub-crescentic portion, much like the sub-mentum of certain orthopterous forms. There are three independent (at least, distally) terminal lobes instead of two, the outer two of which may be taken to be the paraglossae, and the inner median one the fused glossae or inner lobes. Series of cross sections of the mouthparts in situ show well the general relation of the parts (fig. I B and C), and show that the terminal lobes of the labium are distinct distally, and that the hypopharynx is traversed from base to tip by a cylindrical channel. This is of course the efferent duct of the salivary glands. The sections show plainly the origin 
of the hypopharynx from the dorsal surface of the labium (floor of the mouth).

In the male* the mandibles are wanting, the other mouthparts being as in the female.

I have examined the mouthparts of pupae, male and female, of various ages, and find some interesting conditions, but this is ontogenetic study, and we shall for consistency's sake present now only the results of the study of the comparative anatomy of the adults.

\section{Simulitidae.}

Simulium sp. In the females of Simulium sp. the mouthparts (fig. 2) are of the type presented by Blepharocera but present some interesting modifications. The mouthparts are short and broad in general character, instead of elongate. The labrum-epipharynx (fig. 2 l. ep) is broadly and bluntly triangular and can be readily separated into two lamellae, a dorsal and a ventral one, obviously labrum (fig. 2 lb) and epipharynx (fig. $2 e p$ ) respectively. The epipharnyx presents, at its distal extremity, four minute strongly chitinized processes, evidently mere special chitinizations of the epipharyngeal cuticula. The mandibles (fig. $2 \mathrm{md}$ ) are short, broad (as compared with the mandibles of the Blepharoceridae), thin and weakly chitinized. They have a well-defined articulating condyle at

\footnotetext{
* In the Zoologischer Anzeiger no. 557, p. 280, r898, I have said mistakenly that the mandibles are present in the male.
}

base. The maxillae (fig. $2 m x$ ) consist of a basal sclerite, a long 5 -segmented
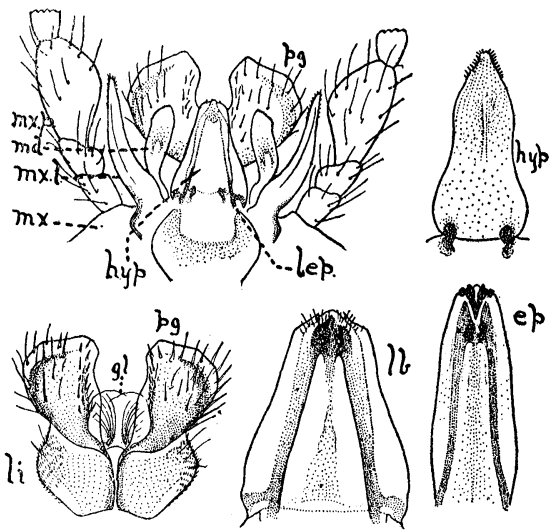

Fig. 2. Mouthparts of Simulium sp., $q$; l. ep labrum-epipharynx, $m d$ mandible, $m x$ maxilla, $m x . l$ maxillar lobe, $m x . p$ maxillar palpus, $l i$ labium, $p g$ paraglossa, $g$ glossa, hyp hypopharynx, $l b$ labrum, $e p$ epipharynx.

palpus and a single maxillar lobe reaching nearly to the end of the third palpar segment. This is serrate on its inner margin at the tip, and is better developed than in most of the Nematocera. The labium (fig. 2, li) is short, broad, with a short basal sclerite and three terminal lobes, two large free paraglossae, and a median short membranous lobe, the fused glossae. The terminal lobes present no sign of pseudo-tracheae. There are no palpi. The hypopharynx (fig. 2, hyp) is about as long as the labrum-epipharynx but narrower and its narrowly pointed apex is finely serrate on both margins.

Simulium sp. A second species of 
Simulium examined presented no differences in mouthparts structure.

\section{Chironomidae.}

Ceratopogon sp. The mouthparts of females present, as shown in figure 3 , parts similar to those described for the Blepharoceridae and the Simuliidae. The well-chitinized labrum-epipharynx (fig. $3, l b$ ) is elongate, broad at base and tapering to a blunt tip which bears two minute processes of the character of those of the Simuliid epipharynx. The mandibles (fig. 3, $m(d)$ articulating on either side of the labrum-epipharynx are, with it, borne by a portion of the head capsule produced anteriorly so that the bases of labrum and mandibles lie considerably in front of the bases of maxillae and labium. Each mandible articulates with a slight projecting process of the head capsule. The mandibles are strongly chitinized, elongate, narrow with convex outer margin, and with a few strong, sharp teeth (dentations) on the apical inner margin. The maxillae (fig. $3 m x$ ) consist of slender 5 -segmented palpus $(m x, p)$ and single blade-like maxillar lobe $(m x . l)$ reaching to end of second palpar segment. The labium (fig. 3 li) bears but two terminal lobes, the paraglossae, and these appear to be 2 -segmented. They are free and independent to their bases. The hypopharynx (fig. 3 , hyp) is a little

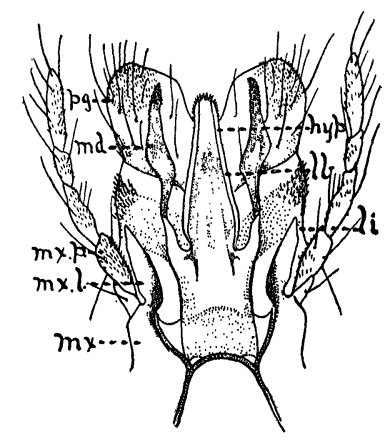

Fig. 3, Mouthparts of Ceratopogon sp., $q$; lb labrum-epipharynx, $m d$ mandible, $m x$ maxilla, $m x . l$ maxillar lobe, $m x . p$ maxillar palpus, $l i$ labium, $p g$ paraglossa, $h y p$ hypopharynx.

broader than the labrum-epipharynx, is weakly chitinized, and is weakly but conspicuously serrate at its apex.

The males of Ceratopogon have no mandibles, and the maxillae have no terminal lobe, and only 4-segmented palpi.

Chironomus sp. In females of Chironomus we meet a mouth structure differing essentially from that of females of Ceratopogon in that there is lacking in Chironomus the mandibles and the maxillar lobes. The mouthparts of Chironomus are also short and broad and not elongate as in Ceratopogon. Chironomus does not possess, as Ceratopogon does, piercing mouthparts.
Exchange Desired. - Dr. A. Griffini of the University of Turin, Italy, desires to obtain American specimens of Cybister and
Dytiscus, pinned or in alcohol, in exchange for Italian insects of any order. Address as above. 

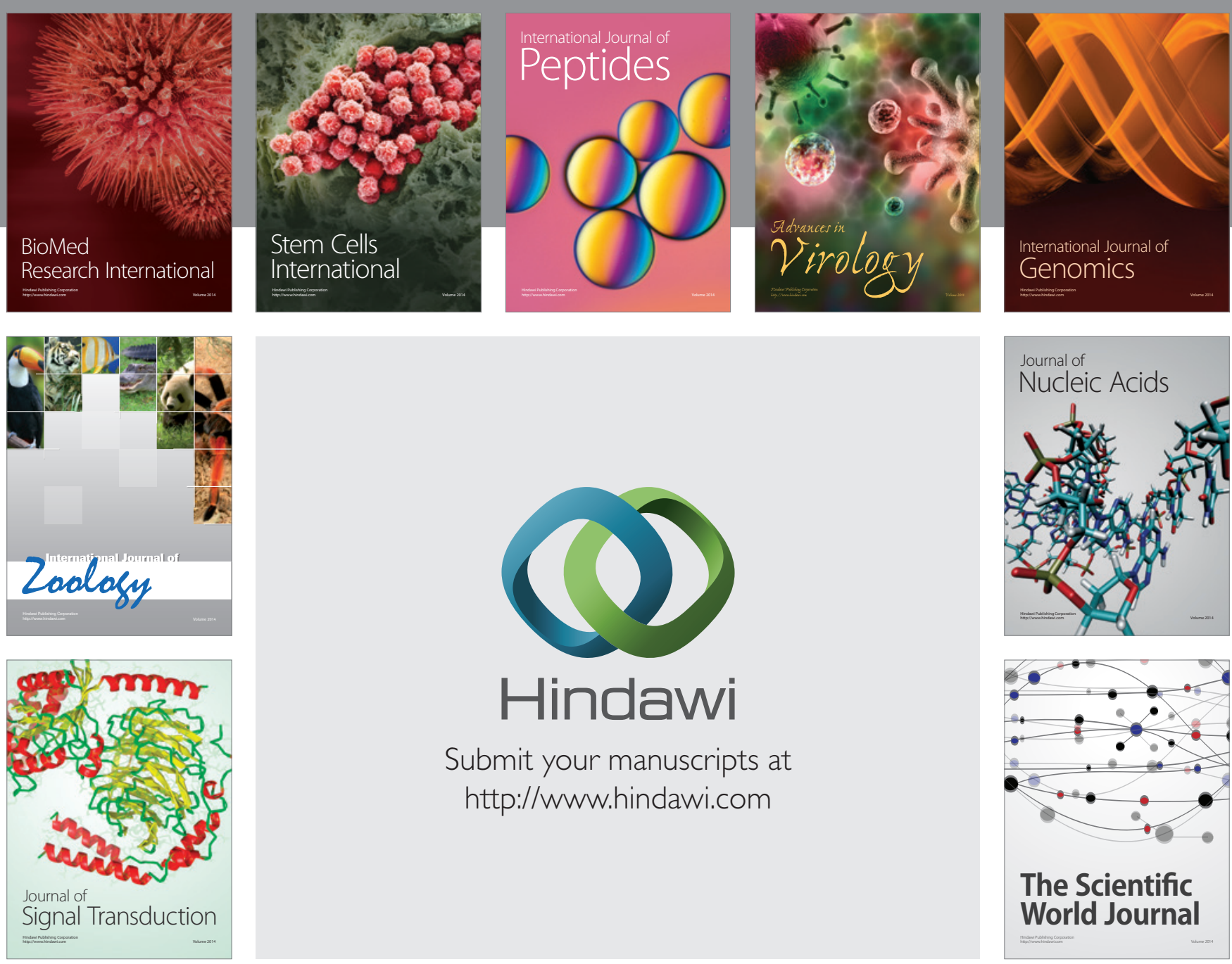

Submit your manuscripts at

http://www.hindawi.com
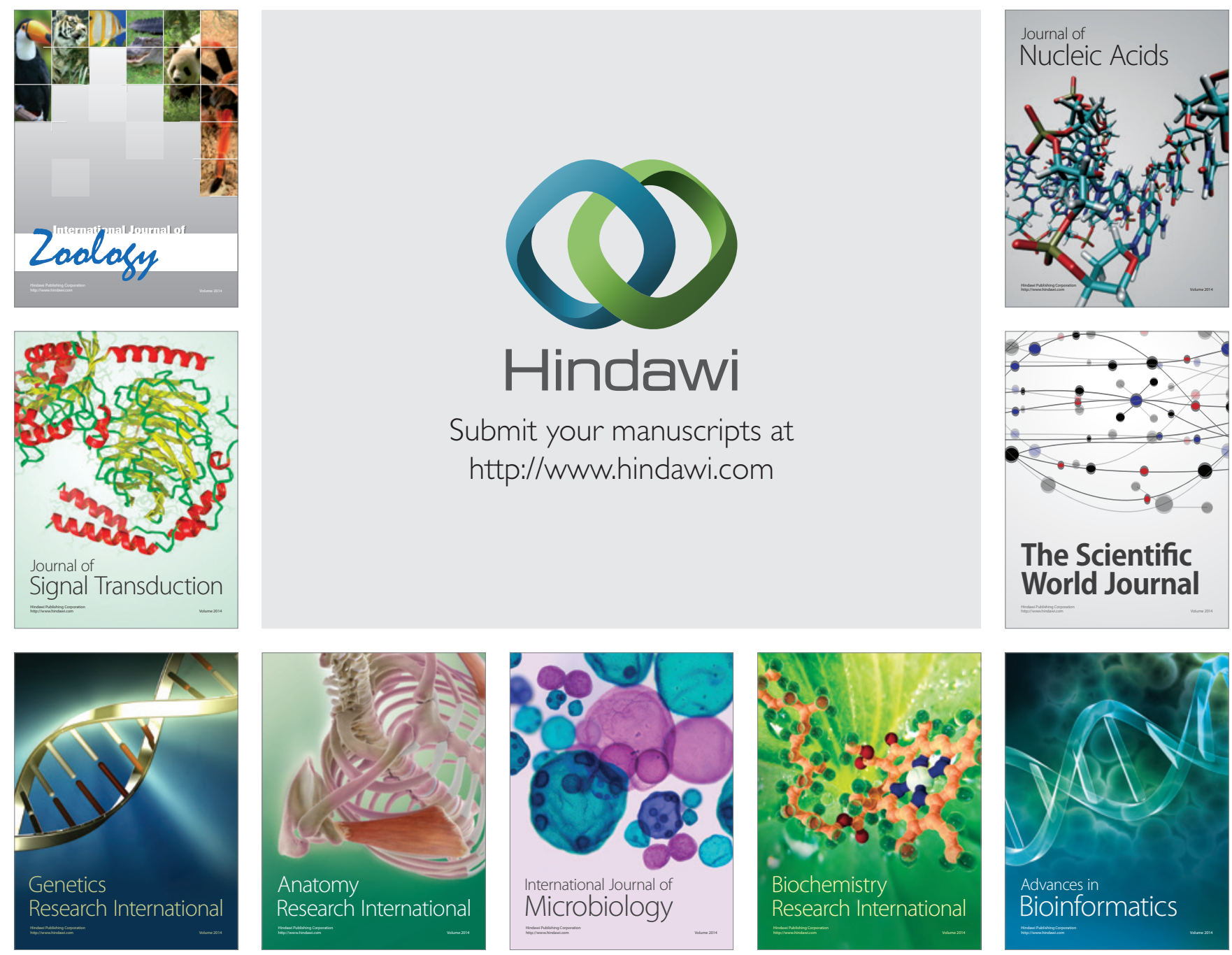

The Scientific World Journal
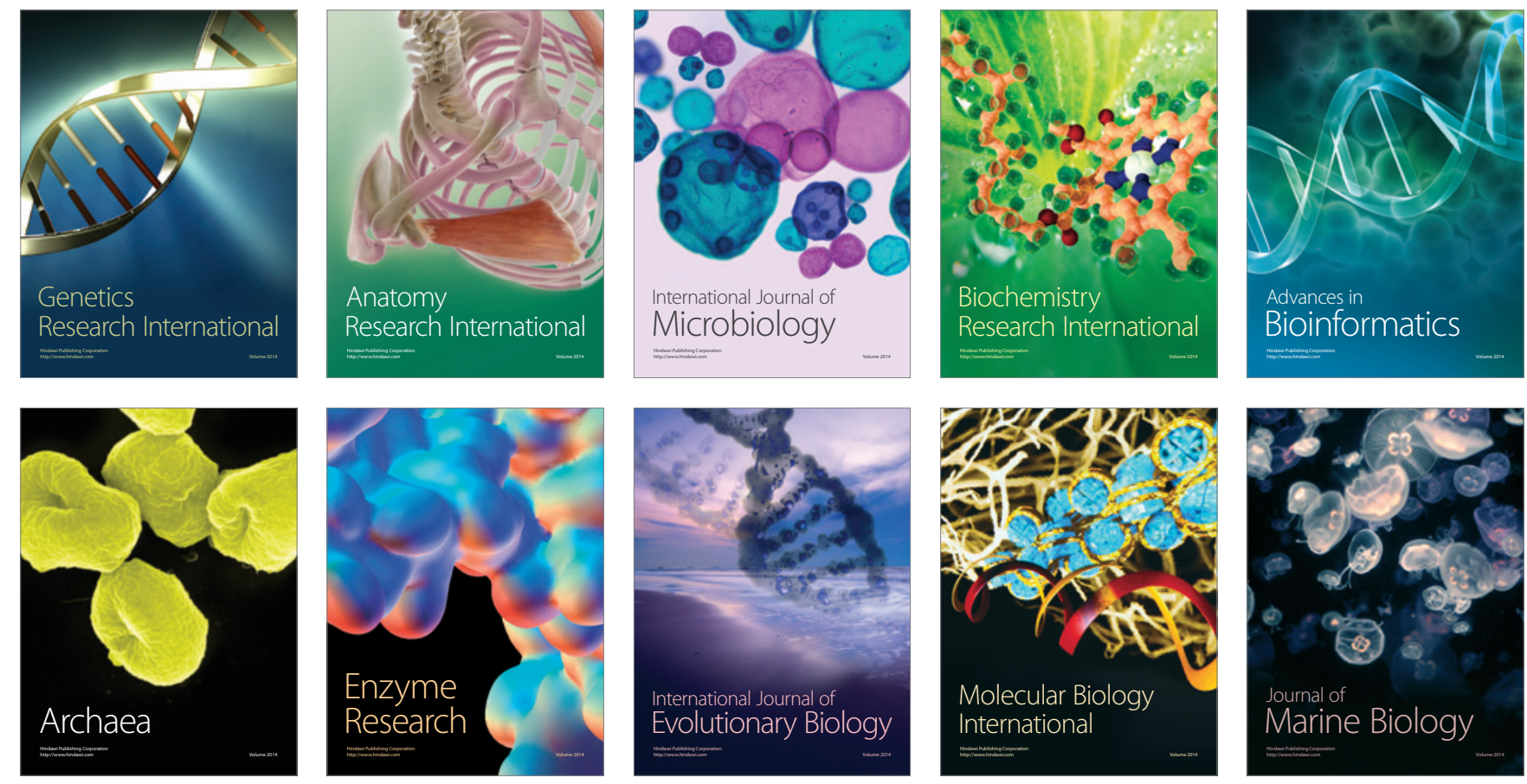